\title{
HUBUNGAN ANTARA PENDIDIKAN DAN PARITAS IBU HAMIL DENGAN PEMERIKSAAN KEHAMILAN DI PUSKESMAS PANGKALAN BALAI KABUPATEN BANYUASIN TAHUN 2017
}

\author{
Leny \\ Akademi Kebidanan Budi Mulia Palembang
}

\section{A B S T R A K}

Informasi Artikel :

Diterima : April 2018

Disetujui : Mei 2018

Dipublikasikan : Juni 2018

*Korespondensi Penulis : basorirayca@gmail.com
Kejadian kesakitan dan kernatian ibu hamil juga berakar pada ketidak berdayaan perempuan dalam mendapat kan kesetaraan dalam hal pendidikan, pekerjaan, ekonomi serta dalam memperoleh pelayanan kesehatan, dasar. Faktor ini telah menciptakan dampak buruk dengan rendahnya kualitas kesehatan ibu hamil, bahkan sebelum kehamilan itu terjadi dan makin di perparah saat kehamilan dan persalinanya. Pemeriksaan kandungan secara rutin bagi ibu hamil juga terbukti masih di bawah standar nasional 4 kali selama masa kehamilan. Tujuan penelitian ini diketahuinya hubungan antara pendidikan dan paritas ibu hamil dengan pemeriksaan kehamilan di Puskesmas Pangkalan Balai Kabupaten Banyuasin Tahun 2017. Penelitian ini menggunakan metode survei analitik dengan rancangan Cross Sectional dilakukan terhadap 40 responden. Hasil penelitian didapatkan ibu hamil yang berpendidikan tinggi sudah memahami arti pentingnya kesehatan dan manfaat Antenatal Care sehingga lebih cenderung untuk memeriksakan kehamilannya sesuai dengan standar yaitu minimal 4 kali selama masa kehamilannya. Ibu-ibu yang mempunyai anak lebih dari 3 orang telah merasa aman dalam menghadapi kehamilannya sehingga cenderung malas untuk memeriksakan kehamilannya dan sudah tersita waktunya untuk mengurus anak-anak sebelumnya sehingga cenderung untuk tidak memeriksakan kehamilannya secara teratur, sedangkan ibu dengan paritas rendah masih antusias dan mempunyai perhatian yang cukup dengan kehamilannya sehingga mau untuk teratur memeriksakan kehamilannya. Penelitian in diharapkan dapat bermanfaat untuk puskesmas dalam upaya pengembangan dan peningkatan pelayanan kesehatan khususnya pelayanan antenatal care, serta bagi mahasiswa dan institusi pendidikan dalam penunjang pemberian informasi dan menambah wawasan khususnya tentang pemeriksaan kehamilan

Kata Kunci : Pemeriksaan kehamilan, Pendidikan, Paritas

\section{ABSTRACT}

The incidence of morbidity and mortality of pregnant women is also rooted in women's inadequacy in obtaining equality in education, employment, economics and in obtaining basic, health services. This factor has created adverse effects with poor quality of health of pregnant women, even before the pregnancy occurs and increasingly in perparah during pregnancy and perguruananya. Routine screening of pregnant women is also proven to be below national standards 4 times during pregnancy. The purpose of this study is to know the relationship between education and parity of pregnant women with the examination of pregnancy at Puskesmas Pangkalan Balai Banyuasin Regency Year 2017. This research use analytical survey method with Cross Sectional design done to 40 respondents. The results obtained by pregnant women who have high education have understood the importance of health and benefits Antenatal Care so more likely to check pregnancy in accordance with the standard that is at least 4 times during pregnancy. Mothers of more than 3 children have been comfortable with their pregnancies, so they tend to be lazy to check their pregnancies and have time to take care of previous children so that they tend not to check their pregnancies regularly, while mothers with low parity are still enthusiastic and have enough attention to the pregnancy so willing to regularly check her pregnancy. This research is expected to be useful for puskesmas in the 
effort of development and improvement of health service especially antenatal care service, and also for student and educational institution in supporting the giving of information and giving more insight about pregnancy examination

Keywords: Pregnancy examination, Education, Parity

\section{PENDAHULUAN}

Menurut Wold Health Organization (WHO) antenatal care adalah cara untuk mendeteksi dini terjadinya resiko tinggi terhadap kehamilan dan persalinan juga dapat menurunkan angka kematian ibu dan memantau keadaan janin. Idealnya bila tiap wanita hamil mau memeriksakan kehamilannya, bertujuan untuk mendeteksi kelainan-kelainan yang mungkin ada atau akan timbul pada kehamilan tersebut diatasi sebelum berpengaruh tidak baik terhadap kehamilan dengan melakukan pemeriksaan antenatal care (Wiknjosastro, 2006).

Mortalitas pada wanita hamil dan bersalin adalah masalah besar di Negara berkembang, di negara miskin sekitar $25-50 \%$ kematian wanita usia subur disebabkan hal berkaitan dangan kehamilan. Menurut Wold Health Organization (WHO), lebih dari 585.000 ibu pertahunnya meninggal saat hamil atau bersalin (Saifuddin, 2006).

WHO memperkirakan bahwa sekitar $15 \%$ dari seluruh wanita yang hamil akan berkembang menjadi komplikasi yang berkaitan dengan kehamilanya serta dapat mengancam jiwanya. Dari 5.600.000 wanita hamil di Indonesia, sejumlah besar akan mengalami suatu komplikasi atau masalah yang bisa menjadi fatal, survey demografi dan kesehatan yang dilaksanakan pada tahun 1997 menyatakan bahwa dari tahun 1992-1997, 26\% wanita dengan kelahiran hidup mengalami komplikasi (Pusdiknakes, 2013).

Kejadian kesakitan dan kernatian ibu hamil juga berakar pada ketidak berdayaan perempuan dalam mendapat kan kesetaraan dalam hal pendidikan, pekerjaan, ekonomi serta dalam memperoleh pelayanan kesehatan, dasar. Faktor ini telah menciptakan dampak buruk dengan rendahnya kualitas kesehatan ibu hamil, bahkan sebelum kehamilan itu terjadi dan makin di perparah saat kehamilan dan persalinanya. Pemeriksaan kandungan secara rutin bagi ibu hamil juga terbukti masih di bawah standar nasional 4 kali selama masa kehamilan (Nugraha, 2007).

Angka Kematian Ibu (AKI) sebagai salah satu indikator kesehatan ibu, dewasa ini masih tinggi di Indonesia bila dibandingkan dengan AKI di negara ASEAN lainya. Menurut data dari Survei
Demografi Kesehatan Indonesia (SDKI) 20002003, AKI di Indonesia adalah 307 per 100.000 kelahiran hidup. Hal ini berarti bahwa lebih dari $18.000 \mathrm{ibu}$ meninggal per tahun atau. 2 ibu meninggal tiap jam oleh sebab yang berkaitan dengan kehamilan, persalinan dan nifas (Depkes, 2004).

Komplikasi yang berhubungan dengan kematian maternal dapat dicegah, bila kesehatan ibu selama hamil selalu terjaga melalui pemeriksaan antenatal yang teratur dan pertolongan yang bersih dan aman, penurunan AKI dan AKB serta perinatal di tingkat pelayanan dasar dan pelayanan rujukan primer, dapat dilakukan dengan mengembangkan konsep Audit Matemal-Perinatal (Depkes RI, 2003).

Menurut Saifudin, kunjungan anternatal untuk pemantauan dan pengawasan kesejahteraan ibu dan anak minimal empat kali selama kehamilan dalam waktu sebagai berikut : kehamilan trismester pertama ( $\leq 14$ minggu ) satu kali kunjungan, kehamilan trismester kedua (14-28 minggu) satu kali kunjungan dan kehamilan trismester ketiga (28-36 minggu dan sesudah minggu ke-36) dua kali kunjungan (Salmah, 2006).

Banyak faktor yang berhubungan dengan kunjungan antenatal diantaranya kurangnya partisipasi yang disebabkan tingkat pendidikan ibu rendah, kemampuan ekonomi ibu rendah kedudukan sosial budaya yang tidak mendukung, faktor lain seperti usia ibu ketika hamil dan melahirkan, ibu yang terlalu muda (kurang dari 20 tahun) dan terlalu tua (di atas 35 tahun), Frekuensi melahirkan telah empat kali melahirkan atau lebih dan jarak antar kelahiran atau persalinan kurang dari 24 bulan, termasuk kelompok yang berisiko tinggi yang menyertai komplikasi ibu (Sumarjadi, 2005).

Menurut data yang didapatkan dari Puskesmas Pangkalan Balai kabupaten Banyuasin tahun 2015 di dapatkan jumlah kunjungan ulang ibu hamil (K4) sebanyak 695 dari sasaran 745 dan pada tahun 2016 sebanyak 768 dari 821, walaupun terdapat peningkatan kunjungan ulang ibu hamil di Puskesmas Pangkalan Balai tetapi masih ada ibu hamil yang tidak memeriksakan kehamilannya kerena pengaruh faktor sosial budaya yaitu lebih mempercayai dukun.

Berdasarkan latar belakang tersebut, maka penulis tertarik untuk melakukan penelitian dengan 
judul "Hubungan Antara Pendidikan dan Paritas Ibu Hamil dengan Pemeriksaan Kehamilan di Puskesmas Pangkalan Balai Kabupaten Banyuasin Tahun 2017”.

\section{METODE PENELITIAN}

Penelitian ini menggunakan metode survei analitik dengan rancangan Cross Sectional dimana variabel pendidikan dan paritas ibu serta variabel pemeriksaan kehamilan hanya diobservasi dan diambil satu kali saja dalam waktu bersamaan pada saat penelitian (Notoatmodjo, 2005)

Populasi adalah keseluruhan objek penelitian atau objek yang diteliti (Notoatmodjo, 2005).

Populasi dalam penelitian ini adalah semua ibu hamil trimester III (usia Kehamilan > 32 minggu) yang datang memeriksakan kehamilannya di Puskesmas Pangkalan Balai Kabupaten Banyuasin pada saat penelitian dilaksanakan yang berjumlah 40 orang.

Analisa univariat adalah analisa yang dilakukan untuk mengetahui distribusi frekuensi variabel independen dan variabel dependen dari hasil penelitian. Pada umumnya dalam analisa ini hanya menghasilkan distribusi dan presentase dari tiap variabel (Notoatmodjo, 2005).

Analisa univariat pada penelitian dilakukan terhadap tiap variabel penelitian yaitu variabel dependen (pemeriksaan kehamilan) dan variabel independen (pendidikan dan paritas) yang dianalisis dengan menggunakan tabel distrbusi frekuensi.

\section{HASIL PENELITIAN}

\section{Pelaksanaan Penelitian}

Teknik pengumpulan data pada penelitian ini dilakukan dengan menggunakan data primer yaitu sumber informasi yang langsung berasal dari yang mempunyai wewenang dan tanggung jawab terhadap data yang diperoleh dengan menggunakan kuesioner yang telah disiapkan. Data primer diperoleh melalui wawancara dengan menggunakan kuesioner untuk memperoleh data ibu hamil dalam memeriksakan kehamilan, serat data pendidikan dan paritas. Wawancara dilakukan secara terpisah pada masing-masing responden yang berjumlah 40 responden secara terpisah sehingga di perolelah hasil yang bervariasi. Hasil wawancara di tulis selengkap lengkapnya sesuai dengan hasil wawancara.

2. Penyajian Data

\section{a. Analisa Univariat}

Analisa ini untuk mengetahui distribusi frekuensi dan persentase dari tiap variabel independen (pendidikan dan paritas) dan variabel dependen (Pemeriksaan kehamilan). Data distribusi dalam bentuk tabel dan teks akan diuraikan sebagai berikut:

\section{Pemeriksaan kehamilan}

Pemeriksaan Kehamilan dikategorikan menjadi dua yaitu Standar (apabila kunjungan pemeriksaan kehamilan sesuai dengan standar $\geq$ 4 kali selama kehamilan) dan Tidak Standar (apabila kunjungan pemeriksaan kehamilan tidak sesuai dengan standar $\geq 4$ kali selama kehamilan) dapat dilihat pada tabel 1:

Tabel 1

\begin{tabular}{|c|c|c|c|}
\hline \multicolumn{4}{|c|}{$\begin{array}{l}\text { Distribusi Frekuensi } \quad \text { Responden } \\
\text { Berdasarkan Pemeriksaan Kehamilan } \\
\text { Di Puskesmas Pangkalan Balai Kabupaten } \\
\text { Banyuasin Tahun } 2017\end{array}$} \\
\hline No & $\begin{array}{c}\text { Pemeriksaan } \\
\text { Kehamilan }\end{array}$ & Frekuensi & $\begin{array}{c}\text { Persentase } \\
(\%)\end{array}$ \\
\hline 1. & Standar & 22 & 55 \\
\hline 2. & Tidak Standar & 18 & 45 \\
\hline \multicolumn{2}{|c|}{ Jumlah } & 40 & 100 \\
\hline
\end{tabular}

Dari tabel 1 didapatkan ibu yang melakukan pemeriksaan kehamilan standar sebesar $22 \mathrm{ibu}(55 \%)$ dan ibu melakukan pemeriksaan kehamilan tidak standar sebesar 18 ibu $(45 \%)$.

\section{Pendidikan}

Pendidikan dibagi menjadi dua kategori, yaitu tinggi (Bila pendidikan Responden $\geq$ SLTA/Sederajat) dan rendah (Bila Pendidikan Responden < SLTA/Sederajat) yang akan diuraikan pada tabel 2 :

Tabel 2

Distribusi Frekuensi $\quad$ Responden
Berdasarkan Pendidikan
Di Puskesmas Pangkalan
Banyuasin Tahun 2017

\begin{tabular}{|c|c|c|c|}
\hline No & Pendidikan & Frekuensi & $\begin{array}{c}\text { Persentase } \\
(\%)\end{array}$ \\
\hline 1. & Tinggi & 25 & 62,5 \\
\hline 2. & Rendah & 15 & 37,5 \\
\hline \multicolumn{2}{|c|}{ Jumlah } & 40 & 100 \\
\hline
\end{tabular}
pendidikan tinggi sebesar 25 ibu $(62,5 \%)$ dan ibu dengan pendidikan rendah sebesar 15 ibu $(37,5 \%)$

\section{Paritas}

Paritas ibu dibagi menjadi dua kategori, yaitu tinggi (Bila jumlah anak $>3$ orang) dan rendah (Bila jumlah anak $\leq 3$ orang) yang akan diuraikan pada tabel 3 : 
Tabel 3

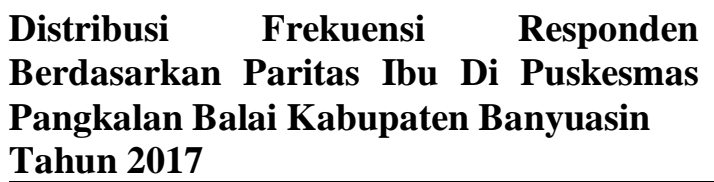

Tahun 2017 Persentase

\begin{tabular}{llll}
\hline No & Paritas & Frekuensi & $\begin{array}{c}\text { Persentase } \\
(\boldsymbol{\%})\end{array}$ \\
\hline 1. & Tinggi & 16 & 40 \\
2. & Rendah & 24 & 60 \\
\hline Jumlah & $\mathbf{4 0}$ & $\mathbf{1 0 0}$ \\
\hline
\end{tabular}

Dari tabel 3 didapatkan ibu dengan

Paritas tinggi sebesar 16 ibu (40\%) dan ibu dengan Paritas rendah sebesar 24 ibu (60\%).

\section{b. Analisa Bivariat}

Analisis ini dilakukan untuk mengetahui hubungan variabel independen yaitu pendidikan dan paritas dengan variabel dependen yaitu pemeriksaan kehamilan. Penelitian dilakukan untuk melihat apakah ada hubungan antara variabel independen dan variabel dependen, dengan menggunakan uji Chi-Square pada $\alpha=$ 0,05 dan $\mathrm{df}=1$, bila $\mathrm{p}$ Value $\leq 0,05$ berarti ada hubungan yang bermakna jika $\mathrm{p}$ Value $>0,05$ berarti tidak ada hubungan yang bermakna.

Hubungan antara Pendidikan dengan Pemeriksaan Kehamilan. Pendidikan ibu dibagi menjadi dua kategori yaitu tinggi (Bila pendidikan Responden $\geq$ SLTA/Sederajat) dan rendah (Bila Pendidikan Responden < SLTA/Sederajat) sedangkan pemeriksaan kehamilan dibagi menjadi Standar (apabila kunjungan pemeriksaan kehamilan sesuai dengan standar $\geq 4$ kali selama kehamilan) dan Tidak Standar (apabila kunjungan pemeriksaan kehamilan tidak sesuai dengan standar $\geq 4$ kali selama kehamilan). Hasil uji statistik dapat dilihat pada tabel 4 :

Tabel 4

$\begin{array}{lcc}\text { Distribusi } & \begin{array}{c}\text { Responden } \\ \text { Pendidikan }\end{array} & \begin{array}{c}\text { Berdasarkan } \\ \text { Pemeriksaaan }\end{array}\end{array}$

Kehamilan Di Puskesmas Pangkalan Balai Kabupaten Banyuasin Tahun 2017

\begin{tabular}{|c|c|c|c|c|c|c|c|c|}
\hline \multirow{3}{*}{ No } & \multirow{3}{*}{ Pendidikan } & \multicolumn{4}{|c|}{ Pemeriksaan Kehamilan } & \multirow{2}{*}{\multicolumn{2}{|c|}{ Jumlah }} & \multirow{3}{*}{$\begin{array}{c}\text { Tingkat } \\
\text { Kemakn } \\
\text { aan }\end{array}$} \\
\hline & & \multicolumn{2}{|c|}{ Standar } & \multicolumn{2}{|c|}{ Tidak Standar } & & & \\
\hline & & $\mathbf{F}$ & $\%$ & $\mathbf{F}$ & $\%$ & $\mathbf{F}$ & $\%$ & \\
\hline 1. & Ting & 1 & 60 & 10 & 40 & 25 & 10 & \\
\hline 2. & Rendah & 7 & 46,7 & 8 & 53,3 & 15 & 100 & \\
\hline Jun & & 22 & - & 18 & - & 40 & 100 & \\
\hline
\end{tabular}

Dari table 4 diketahui dari 25 Responden dengan pendidikan tinggi yang melakukan pemeriksaan kehamilan standar sebanyak 15 responden $(60 \%)$ dan tidak standar sebanyak 10 responden $(40 \%)$, sedangkan dari 15 responden dengan pendidikan rendah yang melakukan pemeriksaan kehamilan standar sebanyak 7 responden $(46,7 \%)$ dan tidak standar sebanyak 8 responden $(53.3 \%)$

Berdasarkan hasil uji statistik dengan menggunakan Chi-Square didapatkan hasil $\mathrm{p}$ Value $=0,000$ lebih kecil dari $\alpha=0,05$ sehingga hipotesis yang menyatakan ada hubungan yang bermakna antara pendidikan responden dengan pemeriksaan kehamilan di Puskesmas Pangkalan Balai Kabupaten Banyuasin Tahun 2017 terbukti secara statistik.

\section{Hubungan antara Paritas dengan Pemeriksaan Kehamilan}

Paritas ibu dibagi menjadi dua kategori, yaitu paritas tinggi (Bila jumlah anak $>3$ orang) dan paritas rendah (Bila jumlah anak $\leq 3$ orang), sedangkan pemeriksaan kehamilan dibagi menjadi Standar (apabila kunjungan pemeriksaan kehamilan sesuai dengan standar $\geq$ 4 kali selama kehamilan) dan Tidak Standar (apabila kunjungan pemeriksaan kehamilan tidak sesuai dengan standar $\geq 4$ kali selama kehamilan). Hasil uji statistik dapat dilihat pada tabel 5.

Tabel 5

Distribusi Responden Berdasarkan Paritas dengan Pemeriksaan Kehamilan Di Puskesmas Pangkalan Balai Kabupaten Banyuasin Tahun 2017

\begin{tabular}{|c|c|c|c|c|c|c|c|c|}
\hline \multirow{3}{*}{ No } & \multirow{3}{*}{ Paritas } & \multicolumn{4}{|c|}{ Pemeriksaan Kehamilan } & & & \multirow{3}{*}{$\begin{array}{l}\text { Tingkat } \\
\text { Kemakn } \\
\text { aan }\end{array}$} \\
\hline & & \multicolumn{2}{|c|}{ Standar } & \multicolumn{2}{|c|}{$\begin{array}{l}\text { Tidak } \\
\text { Standar }\end{array}$} & \multicolumn{2}{|c|}{ Jumlah } & \\
\hline & & $\mathbf{F}$ & $\%$ & $\mathbf{F}$ & $\%$ & $\mathbf{F}$ & $\%$ & \\
\hline 1. & Tinggi & 6 & 37,5 & 10 & 62,5 & 16 & 100 & \multirow{3}{*}{$\begin{array}{c}\mathrm{P} \text { Value }= \\
0,000\end{array}$} \\
\hline 2. & Rendah & 16 & 66,7 & 8 & 33,3 & 24 & 100 & \\
\hline \multicolumn{2}{|c|}{ Jumlah } & 22 & & 18 & & 40 & & \\
\hline
\end{tabular}

Dari tabel 5 diketahui dari 16 Responden dengan paritas tinggi yang melakukan pemeriksaan kehamilan standar sebanyak 6 responden $(37,5 \%)$ dan tidak standar sebanyak 10 responden $(62,5 \%)$, sedangkan dari 24 responden dengan paritas rendah yang melakukan pemeriksaan kehamilan standar sebanyak 16 responden $(66,7 \%)$ dan tidak standar 8 responden $(33,3 \%)$.

Berdasarkan hasil uji statistik dengan menggunakan Chi-Square didapatkan hasil $\mathrm{p}$ Value $=0,000$ lebih kecil dari $\alpha=0,05$ sehingga dapat disimpulkan bahwa ada hubungan yang bermakna antara Paritas responden dengan pemeriksan kehamilan di Puskesmas Pangkalan Balai Kabupaten Banyuasin Tahun 2017. 


\section{PEMBAHASAN}

\section{Pemeriksaan Kehamilan}

Pemeriksaan/pengawasan antenatal merupakan pemeriksaan kehamilan untuk mengoptimalisasi kesehatan mental dan fisik ibu hamil, sehingga mampu menghadapi persalinan, nifas, persiapan memberikan ASI, dan kembalinya kesehatan reproduksi secara wajar (Nenk, 2010).

Dalam penelitian ini, Pemeriksaan kehamilan dibagi menjadi dua kategori yaitu Standar (apabila kunjungan pemeriksaan kehamilan sesuai dengan standar $\geq 4$ kali selama kehamilan) dan Tidak Standar (apabila kunjungan pemeriksaan kehamilan tidak sesuai dengan standar $\geq 4$ kali selama kehamilan). Hasil penelitian ini didapatkan distribusi responden dengan pemeriksaan kehamilan standar diperoleh 22 responden (55\%) dan responden yang melakukan pemeriksaan kehamilan tidak standar yaitu 18 responden (45\%).

Kejadian kesakitan dan kematian ibu hamil juga berakar pada ketidakberdayaan perempuan dalam mendapatkan kesetaraan dalam hal pendidikan, pekerjaan, ekonomi serta dalam memperoleh pelayanan kesehatan, dasar. Faktor ini telah menciptakan dampak buruk dengan rendahnya kualitas kesehatan ibu hamil, bahkan sebelum kehamilan itu terjadi dan makin di perparah saat kehamilan dan persalinanya. Pemeriksaan kandungan secara rutin bagi ibu hamil juga terbukti masih di bawah standar nasional 4 kali selama masa kehamilan (Nugraha, 2007).

Pada penelitian ini responden yang melakukan pemeriksaan kehamilan sesuai standar sudah cukup banyak hal ini dimungkinkan karena sudah banyaknya informasi yang membuat ibu-ibu hamil mau memeriksaan kehamilannya secara teratur dan berkala khususnya untuk mengetahui keadaan ibu dan janinnya.

\section{Pendidikan dengan Pemeriksaan Kehamilan}

Pendidikan adalah proses pembelajaran agar dapat mengembangkan potensi dari diri serta mendapatkan ilmu pengetahuan (Niven, 2008).

Dari hasil analisa univariat didapatkan responden yang memiliki pendidikan tinggi (Bila pendidikan Responden $\geq$ SLTA/Sederajat) sebanyak 25 responden (62,5\%), dan responden dengan pendidikan rendah (Bila Pendidikan Responden <
SLTA/Sederajat) sebanyak 15 responden $(37,5 \%)$. Hasil analisa bivariat, dari 25 responden dengan pendidikan tinggi ditemukan 15 orang $(60 \%)$ yang melakukan pemeriksaan kehamilan standar sedangkan yang melakukan pemeriksaan kehamilan tidak standar 10 orang $(40 \%)$ dan dari 15 responden dengan pendidikan rendah yang melakukan pemeriksaan kehamilan standar 7 orang (46,7\%), sedangkan yang melakukan pemeriksaan kehamilan tidak standar 8 orang $(53,3 \%)$.

Hasil uji Chi-Square menunjukkan $p$ value $(0,000)$ lebih kecil dari $(0,05)$ yang berarti ada hubungan yang bermakna antara pendidikan dengan pemeriksaan kehamilan di Puskesmas Pangkalan Balai Kabupaten Banyuasin Tahun 2014.

Hasil ini sesuai dengan hasil penelitian Yanora (2006), menyatakan bahwa pendidikan mempengaruhi dalam pemeriksaan kehamilan dimana ibu yang berpendidikan tinggi proporsinya lebih besar yaitu (28,99\%), dibandingkan dengan ibu yang berpendidikan rendah yaitu $(17,4 \%)$. Hal ini disebabkan oleh ibu yang berpendidikan tinggi menyadari bahwa pemeriksaan kehamilan penting.

Menurut penelitian Kurnia (2007), diketahui bahwa proporsi ibu hamil yang berpendidikan tinggi dengan pemeriksaan kehamilan lebih besar $(85,7 \%)$ dibandingkan proporsi ibu yang berpendidikan rendah dengan pemeriksaan kehamilan sebesar $(47,4 \%)$.

Rendahnya tingkat pendidikan yang mengakibatkan kurangnya pengetahuan tentang kehamilan atau kelainan-kelainan dalam kehamilan yang kurang diperhatikan dan pada akhirnya dapat membawa risiko yang tidak diinginkan. Akibat dari rendahnya pengetahuan ibu hamil tidak jarang kehamilan banyak menimbulkan adanya kematian baik pada ibu maupun pada bayi yang dilahirkan

Pada umumnya ibu hamil yang berpendidikan tinggi sudah memahami arti pentingnya kesehatan dan manfaat Antenatal Care sehingga lebih cenderung untuk memeriksakan kehamilannya sesuai dengan standar yaitu minimal 4 kali selama masa kehamilannya.

\section{Paritas Ibu dengan Pemeriksaan Kehamilan}

Paritas adalah jumlah berapa kali ibu melahirkan anak baik lahir hidup maupun lahir mati.

Dari hasil analisa univariat didapatkan responden yang memiliki paritas tinggi (Bila 
jumlah anak > 3 orang) sebesar 16 responden $(40 \%)$, dan responden dengan paritas rendah (Bila jumlah anak $\leq 3$ orang) sebanyak 24 responden (60\%). Hasil analisa bivariat, dari 16 responden dengan paritas tinggi didapatkan 6 orang $(37,5 \%)$ yang melakukan pemeriksaan kehamilan standar sedangkan yang melakukan pemeriksaan kehamilan tidak standar 10 orang $(62,5 \%)$ dan dari 24. responden dengan paritas rendah yang melakukan pemeriksaan kehamilan standar 16 orang $(66,7 \%)$, sedangkan yang melakukan pemeriksaan kehamilan tidak standar 8 orang $(33,3 \%)$.

Hasil uji Chi-Square menunjukkan $p$ value $(0,000)$ lebih kecil dari $(0,05)$ yang berarti ada hubungan yang bermakna antara paritas ibu dengan pemeriksaan kehamilan di Puskesmas Pangkalan Balai Kabupaten Banyuasin Tahun 2014.

Hasil ini sesuai dengan penelitian Asmiralita (2009), hasil analisis univariat, diketahui jumlah ibu dengan paritas tinggi sebanyak 24 orang dan yang melakukan pemeriksaan kehamilan sebanyak 11 orang, dari hasil uji statistic chi square didapatkan nilai $P$ Value 0,000 yang berarti ada hubungan yang bermakna antara paritas ibu dengan pemeriksaan kehamilan.

Ibu-ibu yang mempunyai anak lebih dari 3 orang telah merasa aman dalam menghadapi kehamilannya sehingga cenderung malas untuk memeriksakan kehamilannya dan sudah tersita waktunya untuk mengurus anak-anak sebelumnya sehingga cenderung untuk tidak memeriksakan kehamilannya secara teratur, sedangkan ibu dengan paritas rendah masih antusias dan mempunyai perhatian yang cukup dengan kehamilannya sehingga mau untuk teratur memeriksakan kehamilannya.

\section{KESIMPULAN}

Berdasarkan hasil penelitian dan analisa data serta pembahasan yang telah dilakukan pada 40 responden, dapat ditarik kesimpulan sebagai berikut :

1. Proporsi ibu yang melakukan pemeriksaan kehamilan standar sebesar 22 orang $(55 \%)$ dan yang melakukan pemeriksaan kehamilan tidak standar sebesar 18 orang (45\%).

2. Proporsi ibu dengan pendidikan tinggi sebesar 25 orang $(62,5 \%)$ dan pendidikan rendah sebesar 15 orang $(37,5 \%)$.

3. Proporsi ibu dengan paritas tinggi sebesar 16 orang $(40 \%)$ dan dengan paritas rendah sebesar 24 orang $(60 \%)$.
4. Ada hubungan yang bermakna antara pendidikan ibu dengan pemeriksaan kehamilan di Puskesmas Pangkalan Balai Kabupaten Banyuasin tahun 2017 dengan $P$ value $=0,000$

5. Ada hubungan yang bermakna antara paritas ibu dengan pemeriksaan kehamilan di Puskesmas Pangkalan Balai Kabupaten Banyuasin tahun 2017 dengan $P$ value $=0,000$

\section{SARAN}

\section{Bagi Petugas Kesehatan}

Agar dapat lebih meningkatkan pelayanan kesehatan kepada ibu hamil sehingga mencegah terjadinya komplikasi selama masa kehamilan dan persalinan serta meningkatkan penyuluhan tentang pentingnya pemeriksaan kehamilan selama masa kehamilan.

2. Bagi Institusi Pendidikan Akbid Budi Mulia

Dapat lebih memperbanyak referensi-referensi di perpustakaan untuk membuat penelitian karya tulis ilmiah khususnya materi-materi yang berhubungan dengan pemeriksaaan kehamilan.

\section{Bagi Peneliti yang akan datang}

Perlu dilakukan penelitian lebih lanjut untuk mencari faktor lain yang berhubungan dengan pemeriksaan kehamilan dan diharapkan dapat memilih variabel-variabel lain yang berhubungan dengan pemeriksaan kehamilan.

\section{DAFTAR PUSTAKA}

Djaja, S. 2009. Penyakit Penyebab Kematian Bayi Lahir (neonatal) dan Sistem Pelayanan Kesehatan yang Berkaitan di Indonesia. (http://www.litbang.depkes.90.id, diakses tanggal 04 November 2017).

Hidayat, Alimul Azis, 2009. Metode Penelitian Kebidanan Teknik Analisa Data. Jakarta : Salema Medika.

Kusmiyati, Yuni, 2009. Perawatan Ibu Hamil (Asuhan Ibu Hamil). Yogyakarta : Fitramaya.

Manuaba, Chandranita. 2008. Gawat Darurat Obstetri Ginekologi dan Obstetri Ginekologi Sosial Untuk Profesi Bidan. Buku Kedokteran, Jakarta : EGC.

Mardalena, 2009. Hubungan antara Pendidikan dan Paritas Ibu dengan Pemeriksaan Kehamilan di Puskesmas Basuki Rahmat Palembang tahun 2008. Palembang : 

Akademi Kebidanan Budi Mulia Palembang.

Moochtar, Rustam, 2001. Sinopsis Obstetri Jilid I. Jakarta : EGC.

Notoatmodjo, Soekidjo. 2005. Metodelogi Penelitian Kesehatan. Jakarta: Rinaka Cipta.

Nining, 2009. Konsep Asuhan Keperawatan Ibu dengan Antenatal Care. (http://ns.nining.blogspots.com, diakses tanggal 04 November 2017).

Prawirohardjo, Sarwono. 2008. Ilmu Kandungan. Jakarta : Yayasan Bina Pustaka Sarwono Prawirohardjo.

Saifuddin, Abdul Bari, 2006. Buku Acuan Nasional Pelayanan Kesehatan Maternal dan Neonatal.

2007. Buku Acuan Nasional Pelayanan Kesehatan Maternal dan Neonatal.

2008. Buku Acuan Nasional Pelayanan Kesehatan Maternal dan Neonatal.

Salma, 2006. Asuhan Kebidanan Antenatal. Jakarta : EGC. 
